LETTER TO JMG

\title{
Novel locus on chromosome 12q22-q23.3 responsible for familial temporal lobe epilepsy associated with febrile seizures
}

\author{
L Claes, D Audenaert, L Deprez, W Van Paesschen, C Depondt, D Goossens, J Del-Favero, \\ $C$ Van Broeckhoven, $P$ De Jonghe
}

lastas iopathic epilepsies have a genetic basis and are characterised by the absence of an overt underlying neurological abnormality. Most idiopathic epilepsies are complex diseases with considerable clinical and genetic heterogeneity and an unclear inheritance pattern because of genetic and environmental factors. Families in which the disease segregates as an autosomal dominant trait with reduced disease penetrance have been identified occasionally. In some of these families, a single gene defect was identified as the cause of epilepsy. To date, mutations in 13 genes have been identified for distinct epilepsy types. Most genes encode subunits of ion channels. ${ }^{12}$ In addition, the gene remains to be identified for 21 mapped loci for epilepsy, which highlights the genetic heterogeneity of the idiopathic epilepsy syndromes. ${ }^{3}{ }^{4}$

Familial temporal lobe epilepsy (MIM 608096) was first described by Berkovic et al. and was recognised as a distinct epileptic syndrome by the International League Against Epilepsy. ${ }^{5}$ It is defined by familial occurrence of simple partial seizures, complex partial seizures, and secondarily generalised seizures of temporal lobe origin. ${ }^{6}$ Two genetically distinct autosomal dominant familial temporal lobe epilepsy syndromes have been reported. Autosomal dominant lateral temporal lobe epilepsy (MIM 600512), or autosomal dominant partial epilepsy with auditory features, was described first by Ottman et al., ${ }^{7}$ and recently, mutations in the leucine rich glioma inactivated 1 ( $L G I 1)$ gene on chromosome 10q24 were identified. ${ }^{89}$ Auras that present as auditory and visual hallucinations are a clinical hallmark of this syndrome. The other variant of familial temporal lobe epilepsy is characterised clinically by onset in teenage years or early adulthood, absence of antecedent factors, low frequency of deja vu, and a usually good prognosis. This variant, which still can be heterogeneous genetically, is not mapped yet. In a large family with febrile seizures (MIM 121210) and familial temporal lobe epilepsy without hippocampal sclerosis, digenic inheritance with loci on chromosomes lq25-q31 and 18qter was suggested. ${ }^{10}$ Finally, in a large pedigree with a mutation in SCNIA, a few affected mutation carriers had temporal lobe epilepsy, while others had febrile seizures. ${ }^{11}$

Febrile seizures occur between six months and five years of age and affect $2-5 \%$ of all children. They are characterised by clonic, tonic-clonic, or atonic seizures that are provoked by fever but are without evidence of intracranial pathology. Sometimes febrile seizures extend beyond the age of five years, when they are designated febrile seizures plus. Association of febrile seizures and febrile seizures plus with a wide variety of afebrile seizures often is observed in patients with epilepsy. This syndrome was named generalised epilepsy with febrile seizures plus (MIM 604233). ${ }^{12}$ Although afebrile seizures in these families mostly are generalised, partial seizures, including temporal lobe epilepsy, also have been
Key points

- Familial temporal lobe epilepsy and febrile seizures belong to the group of idiopathic epilepsies. They sometimes co-occur in families as the variable intrafamilial expression of a presumably monogenic defect. Molecular genetic studies so far have provided evidence only for a digenic inheritance that implicates chromosomes 18qter and 1q25-q31 in a single pedigree.

- A $10 \mathrm{cM}$ density genomewide scan was performed in an extended pedigree not linked with known loci for familial temporal lobe epilepsy and febrile seizures, and conclusive linkage with markers on chromosome 12q23 was obtained. Fine mapping and haplotype segregation analysis narrowed down the candidate region to a $10.35 \mathrm{cM}(8.7 \mathrm{Mb})$ interval between D12S101 and D12S360.

- The chromosome 12q22-q23.3 locus represents a novel locus for autosomal dominant familial temporal lobe epilepsy with febrile seizures.

reported, which renders the designation of generalised epilepsy with febrile seizures plus less appropriate in these families.

Several loci for febrile seizures and generalised epilepsy with febrile seizures plus have been identified: FEBl on chromosome 8q13-q21 (MIM 602476), FEB2 on chromosome 19p13.3 (MIM 602477), FEB3 on chromosome 2q24 (MIM 604403), FEB4 on chromosome 5q14-q15 (MIM 604352), FEB5 on chromosome 6q22-q24, GEFS+1 on chromosome 19q13.1 with mutations in SCN1B (MIM $600235)$, GEFS+2 on chromosome 2 q24 with mutations in SCNIA (MIM 182389), and GEFS+3 on chromosome 5q31q33 with mutations in GABRG2 (MIM 137164). ${ }^{13-21}$

We performed a $10 \mathrm{cM}$ density genomewide scan in a five generation family affected by familial temporal lobe epilepsy and febrile seizures. ${ }^{22}$

\section{PARTICIPANTS AND MATERIALS}

We previously reported a five generation family affected by familial temporal lobe epilepsy and febrile seizures but without hippocampal sclerosis. ${ }^{22}$ The Ethical Committee of the University of Antwerp approved this study and all participants signed informed consent forms. Samples of DNA were available from 53 family members. Detailed genealogical and clinical data have been described. ${ }^{22}$ In brief, 


\begin{tabular}{|c|c|c|c|c|c|c|c|c|c|}
\hline \multirow[b]{2}{*}{ Marker } & \multicolumn{2}{|l|}{ Position } & \multicolumn{7}{|c|}{ LOD score $Z$ at recombination fraction $(\theta=)$} \\
\hline & $c M$ & $\mathrm{Mb}$ & 0.00 & 0.01 & 0.05 & 0.10 & 0.20 & 0.30 & 0.40 \\
\hline D12S326 & 86.40 & 76.48 & -5.81 & -3.90 & -1.94 & -1.00 & -0.18 & 0.08 & 0.07 \\
\hline D12S351 & 95.56 & 90.41 & -0.40 & -0.15 & 0.37 & 0.61 & 0.69 & 0.55 & 0.30 \\
\hline D12S322 & 96.09 & 90.72 & -4.50 & -3.87 & -2.33 & -1.41 & -0.57 & -0.27 & -0.14 \\
\hline D12S829 & 97.16 & 93.12 & -1.40 & 1.03 & 2.08 & 2.38 & 2.18 & 1.54 & 0.71 \\
\hline D12S101 & 100.92 & 94.10 & -1.50 & 0.83 & 1.74 & 2.05 & 1.98 & 1.48 & 0.74 \\
\hline D12S348 & 100.92 & 95.05 & 3.82 & 3.80 & 3.80 & 3.45 & 2.77 & 1.84 & 0.74 \\
\hline D12S1716 & 101.45 & 95.45 & 5.98 & 5.93 & 5.71 & 5.33 & 4.31 & 3.00 & 1.42 \\
\hline D12S1051 & 101.98 & 96.07 & 6.34 & 6.29 & 6.05 & 5.66 & 4.61 & 3.25 & 1.61 \\
\hline D12S1706 & 104.12 & 97.37 & 6.94 & 6.85 & 6.45 & 5.90 & 4.60 & 3.07 & 1.31 \\
\hline D12S1727 & 107.19 & 100.20 & 5.92 & 5.82 & 5.42 & 4.88 & 3.67 & 2.33 & 0.97 \\
\hline D12S1607 & 107.86 & 100.76 & 6.84 & 6.77 & 6.47 & 6.00 & 4.83 & 3.38 & 1.65 \\
\hline D12S1030 & 109.47 & 101.43 & 3.92 & 3.87 & 3.65 & 3.33 & 2.57 & 1.67 & 0.71 \\
\hline D12S318 & 109.47 & 101.43 & 6.78 & 6.70 & 6.34 & 5.83 & 4.62 & 3.15 & 1.45 \\
\hline D12S360 & 111.27 & 102.58 & 1.71 & 2.81 & 3.15 & 3.01 & 2.39 & 1.57 & 0.65 \\
\hline D12S78 & 111.87 & 102.77 & 2.93 & 4.11 & 4.56 & 4.49 & 3.78 & 2.67 & 1.30 \\
\hline D12S1344 & 119.55 & 110.74 & -1.26 & -0.34 & 0.91 & 1.52 & 1.80 & 1.47 & 0.75 \\
\hline D12S79 & 125.31 & 114.47 & 0.96 & 1.73 & 2.61 & 2.93 & 2.81 & 2.14 & 1.10 \\
\hline D12S86 & 134.54 & 117.58 & -2.76 & -1.47 & 0.31 & 1.20 & 1.73 & 1.48 & 0.77 \\
\hline
\end{tabular}

the disease phenotype is characterised by temporal lobe epilepsy, no deja vu or auditory or visual hallucinations, a high incidence of febrile seizures, mean age at onset of afebrile seizures of eight years, low incidence of epileptic features on electroencephalography, no hippocampal sclerosis, and a usually good prognosis. Simple manifestations of partial seizures were viscerosensory, psychic, or cephalic. Complex partial seizures consisted of unresponsiveness, staring, hyperventilation, head deviation, vocalisation, dystonic posturing, automatisms, and unilateral convulsions. Of 22 patients, 10 had febrile seizures and epilepsy, 11 had epilepsy only, and one had febrile seizures only. All febrile seizures ceased by the age of six years. Although the outcome usually was favourable, with spontaneous remission in 11 patients, three patients had refractory seizures. An autosomal dominant pattern of inheritance with reduced disease penetrance of $80 \%$ was seen. ${ }^{22}$ Before the genome screen, we made power calculations using Slink. ${ }^{23}{ }^{24}$ The maximum achievable logarithm of odds score was 9.1 with the same model used for Mlink (see below), 250 replications, and a single marker with four equifrequent alleles. We included 22 patients, 22 at risk individuals, and nine spouses in the genomewide scan. We used 382 autosomal markers of the ABI Prism Linkage Mapping Set MD-10 (Applied Biosystems, Foster City, CA, USA) with an average marker distance of $10 \mathrm{cM}$. We used a PTC 200 thermocycler (MJ Research, Waltham, MA, USA) to amplify products of polymerase chain reaction (PCR), a Beckman Biomek 2000 workstation (Beckman Coulter, Fullerton, CA, USA) to pool samples, and an ABI3700 automated sequencer (Applied Biosystems) to separate PCR fragments. We performed all experiments in the VIB Genetic Service Facility (http:// www.vibgeneticservicefacility.be/). We analysed data with ABI Prism Genescan and Genotyper software (version 3.7; Applied Biosystems). We used the genotype data to perform two point and multipoint linkage analysis with Mlink software of the Linkage program package (version 5.1). ${ }^{25}$ We assumed an autosomal dominant model with $80 \%$ penetrance, and we defined a disease frequency of 0.001 and phenocopy rate of $2 \%{ }^{22}$ We assumed sex average recombination rates. For each marker, the number of alleles used to calculate logarithm of odds scores was set at the observed number of alleles in the pedigree $(N)$ and the allele frequencies were set at $1 / N$.

\section{RESULTS}

In a previous study, we excluded linkage to 13 epilepsy loci in this family, including the loci on chromosomes lq25-q31, 18qter, and 10q and the loci for febrile seizures and generalised epileptic febrile seizures plus+ (except for the FEB5 and GEFS+3 loci, which were not discovered at the time of that study). ${ }^{22}$ We performed a genomewide scan for 53 family members to localise the disease gene in this family.

Two markers at $12 \mathrm{p}$ from the ABI Prism linkage mapping set gave a logarithm of odds score $>2$; a maximum logarithm of odds score $Z$ of 4.56 was obtained with D12S78 at recombination fraction $\theta=0.05$ and a maximum $Z$ of 2.93 with D12S79 at $\theta=0.10$. We analysed 13 additional short tandem repeat markers chosen from the Marshfield comprehensive genetic map and the UCSC genome browser. Sequences that contained short tandem repeats were retrieved from the UCSC genome browser, masked for repeats and used subsequently to generate a list of potential PCR primers using Primer3 (http://frodo.wi.mit.edu). From this list, primer pairs for each marker were chosen with a proprietary algorithm implemented in the Multiplexer program (Goossens et al., unpublished data). This resulted in a number of pools containing between four and 18 primer pairs that were amplified in a single tube reaction without extensive optimising. A maximum two point logarithm of odds score of 6.94 was reached at marker D12S1706 (table 1). The maximum multipoint logarithm of odds score was 7.87 at the same marker.

Segregation analysis identified a disease haplotype in all 22 patients, two obligate carriers, and five at risk family members (fig 1).

Two obligate recombinants (in members III-30 and IV-35) delineated the candidate region centromerically, and one recombination event (in member III-29) defined the candidate region telomerically. This mapped the disease gene for familial temporal lobe epilepsy and febrile seizures to a $10.35 \mathrm{cM}$ region between markers D12S101 and D12S360, which corresponds to a $8.7 \mathrm{Mb}$ region (UCSC genome browser).

\section{DISCUSSION}

We performed a $10 \mathrm{cM}$ density genomewide scan in a five generation pedigree in which familial temporal lobe epilepsy and febrile seizures were transmitted as an autosomal 


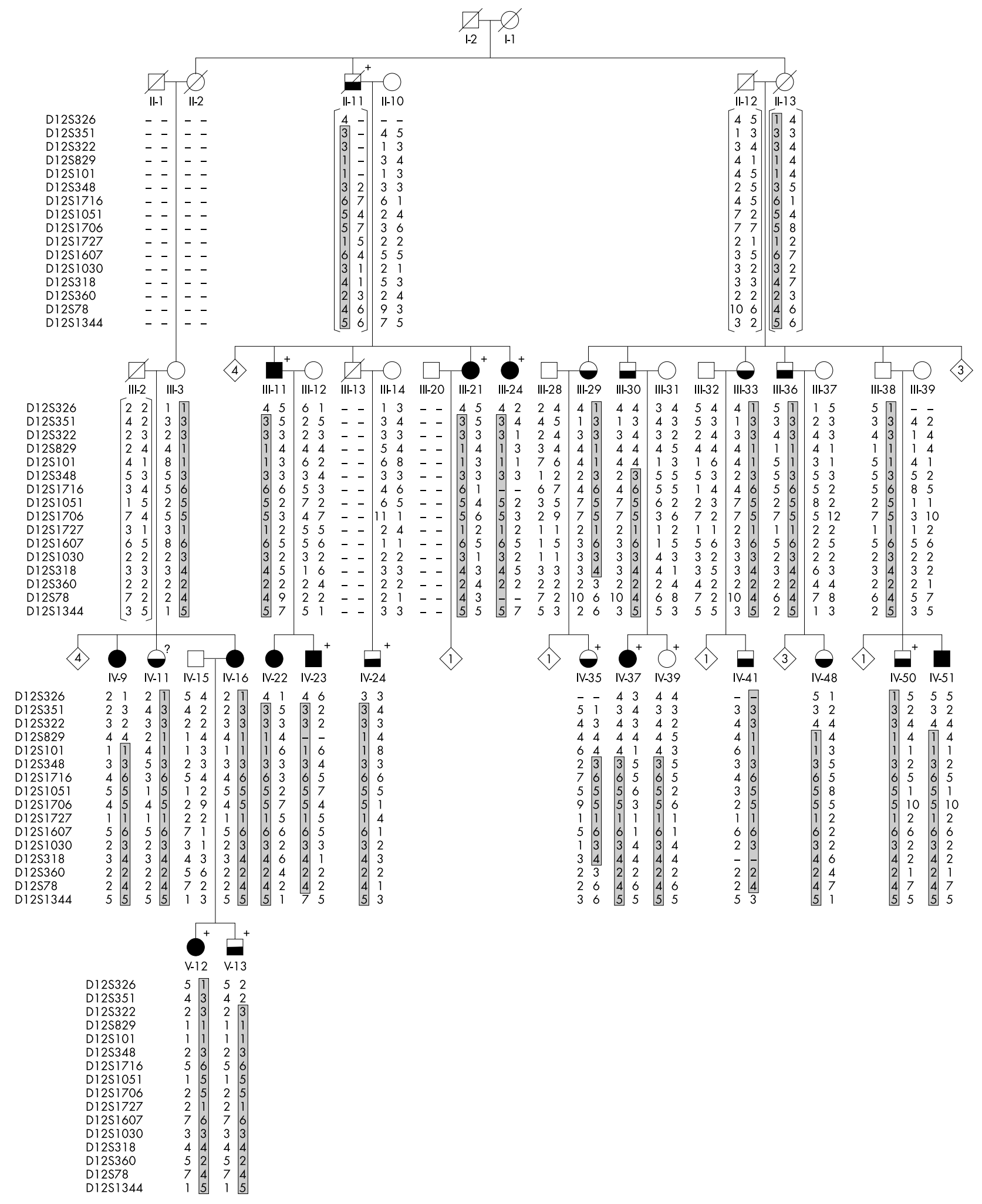

Figure 1 Haplotype analysis of markers at chromosome 12q21.2-q24.1. men with TLE; $\bullet$ women with TLE; $\square$ men with epilepsy; O women with epilepsy; / deceased family member; + family member who had febrile seizures; ? not known if family member had febrile seizures. To protect confidentiality, we used diamonds to indicate unaffected at risk individuals who were analysed in the genome scan; the number refers to the number of family members. The disease halotype is boxed. Inferred haplotypes are between brackets. Family members are numbered according to the numbering in the article of Depondt et al., in which detailed clinical data was reported. ${ }^{22}$

dominant trait. We obtained conclusive linkage between markers D12S101 and D12S360 on chromosome 12q23. Most mutations that cause epilepsy identified to date affect genes that encode ion channels. The $8.7 \mathrm{Mb}$ candidate interval that we identified (NT 019546) contains 50 genes, of which 30 are known and 20 are putative genes; none of these genes encode a classic ion channel. A potential functional candidate gene in this region is LOC121456, which is similar to SLC9A7 - a 


\section{URLs for data in this article}

- Center for Medical Genetics, Marshfield Medical Research Foundation (http://research.marshfieldclinic. org/genetics/)

- National Centre for Biotechnology Information (http:// www.ncbi.nlm.nih.gov/)

- NCBI Human Genome Resources (http:// www.ncbi.nlm.nih.gov/genome/guide/human/)

- International League Against Epilepsy (http://www. ilae-epilepsy.org//

- Online Mendelian Inheritance in Man (http:// www.ncbi.nlm.nih.gov/omim/)

- Primer3 program (http://frodo.wi.mit.edu/)

- University of California - Santa Cruz genome browser (http://genome.ucsc.edu/cgi-bin/ hgGateway)

non-selective sodium potassium and proton exchanger. Other candidate genes in this region are VGLUT3 (vesicular glutamate transporter 3, MIM 607557), which is expressed in the brain and is responsible for glutamate uptake in intracellular synaptic vesicles, and Netrin 4 and ASCL1 (achaete scute complex like 1, MIM 100790), which play a role in axon guidance and neuronal commitment and differentiation, respectively.

Our molecular genetic data confirmed that familial temporal lobe epilepsy with febrile seizures in this family represents a separate genetic entity, presumably caused by a monogenic gene defect. They also confirmed that familial temporal lobe epilepsy and febrile seizures represent the variable expression of this genetic defect, as all patients with only febrile seizures, with febrile seizures and afebrile seizures, or with only afebrile seizures carried the disease haplotype. The combination of febriles seizures or febrile seizures plus and generalised epilepsy is now known as generalised epilepsy with febrile seizures plus, ${ }^{12}$ and mutations in several genes have been shown to underlie this syndrome. ${ }^{18-21} 26$ Subsequent reports, however, showed that partial seizures also could be part of this syndrome: for example, mutations in SCNIA have been identified in families with febrile seizures and generalized epilepsy but also in families with febrile seizures and partial epilepsy. ${ }^{11} 1927$ It has been suggested therefore to expand the spectrum of generalised epilepsy with febrile seizures plus to include partial seizures and to use the term autosomal dominant epilepsy with febrile seizures plus. ${ }^{28}$

Identification of the gene involved in familial temporal lobe epilepsy and febrile seizures will contribute to the unraveling of the molecular mechanisms responsible for epilepsy and will assist the development of better and more effective therapies.

\section{ACKNOWLEDGEMENTS}

DA is a PhD fellow of the Fund for Scientific Research-Flanders. LD is a PhD fellow of the Institute for Science and Technology, Belgium. The authors thank the patients and their family members for their cooperation and participation in this study. We acknowledge the contribution of the VIB Genetic Service Facility (http://www.vibgeneticservicefacility.be/) to the genetic analyses.

\section{Authors' affiliations}

L Claes, D Audenaert, L Deprez, D Goossens, J Del-Favero,

C Van Broeckhoven, P De Jonghe, Department of Molecular Genetics, Flanders Interuniversity Institute for Biotechnology, University of Antwerp, Antwerp, Belgium
P De Jonghe, Department of Neurology, University Hospital Antwerp W Van Paesschen, C Depondt, Department of Neurology, University Hospital of Leuven, Belgium

Funding: This research was funded by the Fund for Scientific ResearchFlanders (FWO), University of Antwerp, the Medical Foundation Queen Elisabeth and the Interuniversity Attraction Poles (IUAP) programme P5/ 19 of the Federal Science Policy Office, Belgium.

Conflicts of interest: none declared.

Correspondence to: P De Jonghe, Department of Molecular Genetics, Epilepsy Research Group, University of Antwerp, Universiteitsplein 1, B-2610 Antwerpen, Belgium; peter.dejonghe@ua.ac.be

Revised version received 18 February 2004

Accepted for publication 20 March 2004

\section{REFERENCES}

1 Mulley JC, Scheffer IE, Petrou S, Berkovic SF. Channelopathies as a genetic cause of epilepsy. Curr Opin Neurol 2003;16:171-6.

2 Haug K, Warnstedt M, Alekov AK, Sander T, Ramirez A, Poser B, Maljevic S, Hebeisen S, Kubisch C, Rebstock J, Horvath S, Hallmann K, Dullinger JS Rau B, Haverkamp F, Beyenburg S, Schulz H, Janz D, Giese B, MullerNewen G, Propping P, Elger CE, Fahlke C, Lerche H, Heils A. Mutations in CLCN2 encoding a voltage-gated chloride channel are associated with idiopathic generalized epilepsies. Nat Genet 2003;33:527-32.

3 Gardiner M, Lehesjoki AE. Genetics of the epilepsies. Curr Opin Neurol 2000; 13:157-64.

4 Kaneko S, Iwasa H, Okada M. Genetic identifiers of epilepsy. Epilepsia 2002;43(suppl 9): 16-20.

5 Berkovic SF, Mclntosh A, Howell RA, Mitchell A, Sheffield U, Hopper JL. Familial temporal lobe epilepsy: a common disorder identified in twins. Ann Neurol 1996;40:227-35.

6 Commission on Classification and Terminology of the International League Against Epilepsy. Proposal for revised classification of epilepsies and epileptic syndromes. Epilepsia 1989;30:389-99.

7 Ottman R, Risch N, Hauser WA, Pedley TA, Lee JH, Barker-Cummings C, Lustenberger A, Nagle KJ, Lee KS, Scheuer ML, Neystat M, Susser M, Wilhelmsen KC. Localization of a gene for partial epilepsy to chromosome 10q. Nat Genet 1995;10:56-60.

8 Kalachikov S, Evgrafov O, Ross B, Winawer M, Barker-Cummings C, Martinelli Boneschi F, Choi C, Morozov P, Das K, Teplitskaya E, Yu A, Cayanis E, Penchaszadeh G, Kottmann AH, Pedley TA, Hauser WA, OHtman R, Gilliam TC. Mutations in LGI1 cause autosomal-dominant partial epilepsy with auditory features. Nat Genet 2002;30:335-41.

9 Morante-Redolat JM, Gorostidi-Pagola A, Piquer-Sirerol S, Saenz A, Poza JJ, Galan J, Gesk S, Sarafidou T, Mautner VF, Binelli S, Staub E, Hinzmann B, French L, Prud'homme JF, Passarelli D, Scannapieco P, Tassinari CA, Avanzini G, Marti-Masso JF, Kluwe L, Deloukas P, Moschonas NK, Michelucci R, Siebert R, Nobile C, Perez-Tur J, Lopez de Munain A. Mutations in the LGI1/Epitempin gene on 10q24 cause autosomal dominant lateral temporal epilepsy. Hum Mol Genet 2002;11:11119-28.

10 Baulac S, Picard F, Herman A, Feingold J, Genin E, Hirsch E, Prud'homme JF, Baulac M, Brice A, LeGuern E. Evidence for digenic inheritance in a family with both febrile convulsions and temporal lobe epilepsy implicating
chromosomes 18qter and 1q25-q31. Ann Neurol 2001;49:786-92.

11 Abou-Khalil B, Ge Q, Desai R, Ryther R, Bazyk A, Bailey R, Haines JL, Sutcliffe JS, George AL Jr. Partial and generalized epilepsy with febrile seizures plus and a novel SCN1A mutation. Neurology 2001;57:2265-72.

12 Scheffer IE, Berkovic SF. Generalized epilepsy with febrile seizures plus. A genetic disorder with heterogeneous clinical phenotypes. Brain 1997; 120:479-90.

13 Wallace RH, Berkovic SF, Howell RA, Sutherland GR, Mulley JC. Suggestion of a major gene for familial febrile convulsions mapping to 8q13-21. J Med Genet 1996;33:308-12.

14 Johnson EW, Dubovsky J, Rich SS, O'Donovan CA, Orr HT, Anderson VE, Gil-Nagel A, Ahmann P, Dokken CG, Schneider DT, Weber JL. Evidence for a novel gene for familial febrile convulsions, FEB2, linked to chromosome 19p in an extended family from the Midwest. Hum Mol Genet 1998;7:63-7.

15 Peiffer A, Thompson J, Charlier C, Otterud B, Varvil T, Pappas C, Barnitz C, Gruenthal K, Kuhn R, Leppert M. A locus for febrile seizures (FEB3) maps to chromosome 2q23-24. Ann Neurol 1999;46:671-8.

16 Nakayama J, Hamano K, Iwasaki N, Nakahara S, Horigome Y, Saitoh H, Aoki T, Maki T, Kikuchi M, Migita T, Ohto T, Yokouchi Y, Tanaka R, Hasegawa M, Matsui A, Hamaguchi H, Arinami T. Significant evidence for linkage of febrile seizures to chromosome 5q14-q15. Hum Mol Genet 2000;9:87-91.

17 Nabbout R, Prud'homme JF, Herman A, Feingold J, Brice A, Dulac O, LeGuern E. A locus for simple pure febrile seizures maps to chromosome 6q22-q24. Brain 2002;125:2668-80.

18 Wallace RH, Wang DW, Singh R, Scheffer IE, George AL Jr, Phillips HA, Saar K, Reis A, Johnson EW, Sutherland GR, Berkovic SF, Mulley JC. Febrile seizures and generalized epilepsy associated with a mutation in the $\mathrm{Na}+-$ channel betal subunit gene SCN1B. Nat Genet 1998;19:366-70.

19 Escayg A, MacDonald BT, Meisler MH, Baulac S, Huberfeld G, AnGourfinkel I, Brice A, LeGuern E, Moulard B, Chaigne D, Buresi C, 
Malafosse A. Mutations of SCN1A, encoding a neuronal sodium channel, in two families with GEFS+2. Nat Genet 2000;24:343-5.

20 Baulac S, Huberfeld G, Gourfinkel-An I, Mitropoulou G, Beranger A, Prud'homme JF, Baulac M, Brice A, Bruzzone R, LeGuern E. First genetic evidence of $G A B A(A)$ receptor dysfunction in epilepsy: a mutation in the gamma2-subunit gene. Nat Genet 2001;28:46-8.

21 Wallace RH, Marini C, Petrou S, Harkin LA, Bowser DN, Panchal RG, Williams DA, Sutherland GR, Mulley JC, Scheffer IE, Berkovic SF. Mutant $\mathrm{GABA}(\mathrm{A})$ receptor gamma2-subunit in childhood absence epilepsy and febrile seizures. Nat Genet 2001:28:49-52.

22 Depondt C, Van Paesschen W, Matthiis G, Legius E, Martens K, Demaerel P, Wilms $G$. Familial temporal lobe epilepsy with febrile seizures. Neurology 2002;58: 1429-33.

23 Ott J. Computer-simulation methods in human linkage analysis. Proc Nat Acad Sci USA 1989:86:4175-8.

24 Weeks DE, OH J, Lathrop GM. SLINK: a general simulation program for linkage analysis. Am J Hum Genet 1990;47:A204.
25 Cottingham RW Jr, Idury RM, Schaffer AA. Faster sequential genetic linkage computations. Am J Hum Genet 1993;53:252-63.

26 Sugawara T, Tsurubuchi Y, Agarwala KL, Ito M, Fukuma G, MazakiMiyazaki E, Nagafuji H, Noda M, Imoto K, Wada K, Mitsudome A, Kaneko S, Montal M, Nagata K, Hirose S, Yamakawa K. A missense mutation of the $\mathrm{Na}+$ channel alpha II subunit gene $\mathrm{Na}(\mathrm{v}) 1.2$ in a patient with febrile and afebrile seizures causes channel dysfunction. Proc Natl Acad Sci USA 2001;98:6384-9

27 Sugawara T, Mazaki-Miyazaki E, Ito M, Nagafuji H, Fukuma G, Mitsudome A, Wada K, Kaneko S, Hirose S, Yamakawa K. Nav1.1 mutations cause febrile seizures associated with afebrile partial seizures. Neurology 2001; 57:703-5.

28 Ito M, Nagafuji H, Okazawa H, Yamakawa K, Sugawara T, MazakiMiyazaki E, Hirose S, Fukuma G, Mitsudome A, Wada K, Kaneko S. Autosomal dominant epilepsy with febrile seizures plus with missense mutations of the ( $\mathrm{Na}+$ )-channel alpha 1 subunit gene, SCN1A. Epilepsy Res 2002;48:15-23.

\section{Call for papers}

10th European Forum on Quality Improvement in Health Care 13-15 April 2005, ExCel, Docklands, London For further information on how to submit your paper please go to: http://www.quality.bmipg.com 